insulin. There is also a striking difference between patients receiving a small dose of insulin and those on large doses.

The major problem in the management of diabetes is the prevention of complications. It is accepted that diabetic retinopathy and renal diseases are due to capillary damage in the retina and glomerulus respectively. It is difficult to imagine that the capillaries of the retina and kidney have been selectively damaged, and there is a growing tendency to regard these changes as part of a generalized microangiopathy of the type that one would expect as part of a metabolic disorder such as diabetes. If this were so, then capillary changes should be observed in all parts of the body, including skin and muscle, and there is a considerable amount of evidence to support this view. Thus it should be possible to use the skin capillaries as a measure of capillary damage throughout the body.

It is not possible to state at this stage whether the measurement of capillary fragility is a test of capillary pathology, though this is a reasonable assumption. Evidence in favour of this assumption is the association between increased capillary fragility and the complications of diabetes (Handelsman et al., 1952 ; British Medical fournal, 1965 ; Moore and Frew, 1965 ) and the decrease in capillary fragility after hypophysectomy for diabetic retinopathy (Christensen, 1968). A direct consequence of this is that the measurement of capillary fragility offers an indication by which we may be able to select those patients who are going to develop retinopathy or other complications, but, more important, by studying the effect of changes in the diabetic state on the capillary fragility it may be possible to identify those factors which are responsible for the development of microangiopathy. Thus it seems that patients requiring large doses of insulin have increased capillary fragility, and it is interesting to speculate about a possible link between an insulin antagonist and microangiopathy.

The usefulness of capillary fragility measurement remains to be evaluated. It may be a non-specific test, as capillary abnormality is a feature of many diseases. Nevertheless, even as a non-specific test it may be of value in following a patient's progress and possibly assessing the prognosis and response to treatment. Our method is well suited to large-scale surveys and clinic screening procedures. It is quick, painless, repeatable, and over 1,500 estimations have been made in two years.

This work was supported by a research grant from the Manchester Regional Hospital Board.

We acknowledge the help given by the medical illustration departments of the Salford Hospital Group and the Manchester Royal Infirmary in the preparation of this paper.

\section{REFERENCES}

Barnes, R. H. (1950). American fournal of Medical Science, 219, 368. Bell, G. H., Lazarus, S., and Munro, H. N. (1940). Lancet, 2, 155. Bell, G. H., Lazarus, S., Munro, H. N., and Scarborough, H. (1942). Lancet, 2, 536.

British Medical fournal, 1965, 2, 603.

Christensen, N. J. (1968). Lancet, 2, 1270

Handelsman, M. B., Levitt, L. M., and Conrad, H. (1952). American fournal of Medical Science, 224, 34.

Lundbæk, K. (1953). Long-term Diabetes. Copenhagen, Munksgaard.

Moore, J. M., and Frew, I. D. O. (1965). British Medical fournal, 2, 19. Munro, H. N., Lazarus, S., and Bell, G. H. (1947). Nutrition Abstracts and Reviews, 17, 291 .

Peck, S. M., and Copley, A. L. (1946). New England fournal of Medicine, $235,900$.

Rodriguez, R., and Root, H. F. (1948). New England fournal of Medicine, 238, 391

\title{
Measurement of Glomerular Filtration Rate by Inulin Clearance without Urine Collection
}

\author{
G. ALAN ROSE,* D.M., F.R.I.C., M.C.PATH.
}

Summary : A continuous infusion method for measuring $\checkmark$ inulin clearance (and hence glomerular filtration rate) which does not require urine collection has been re-evaluated and found to give satisfactory results. In two non-oedematous and anephric patients the plasma level of inulin became virtually constant four hours after a single intravenous dose, and hence this is the minimum time required for the infusion with this method.

\section{Introduction}

Although inulin clearance is generally accepted as the standard method for measurement of glomerular filtration rate the method is beset by three main problems. Firstly, there is the problem of getting accurately timed urine collections without recourse to catheterization, which is often an unjustifiable hazard in the human subject. This problem was overcome by Earle and Berliner (1946) and Berger et al. (1948), who

* Consultant Chemical Pathologist, St. Peter's, St. Philip's, and St. Paul's Hospitals, and Institute of Urology, London W.C.2. In receipt of a grant from the Medical Research Council. pointed out that if a substance was secreted from the extracellular fluid solely via the kidneys, and if the plasma level was constant, then the rate of renal excretion must equal the rate of infusion, and that the term "uv" in the classical clearance equation uv/p could be replaced by " rate of infusion/P." These authors suggested that such a method was suitable provided that renal function was reasonably good and provided that there was no oedema. Robson et al. (1950) pointed out, however, that a constant plasma inulin level did not necessarily mean that full equilibration had been achieved, and possibly this theoretical objection has prevented the more widespread use of this attractive technique. In order to study this theoretical objection, two anephric patients have been given single intravenous doses of inulin and the times taken for plasma inulin levels to become constant have been observed. These results are now reported, together with a further comparison of the classical and the "urineless" inulin clearance methods.

The second problem with inulin concerns its chemical measurement in plasma and urine. Times of hydrolysis and colour development must be carefully controlled in order to obtain reproducible results. The application of a Technicon 
AutoAnalyzer, however, to the method of Heyrovsky (1956) has overcome these particular problems so that reproducible results can be obtained (Rose and Durbin, 1967).

The third main problem is that strong solutions of inulin always contain appreciable amounts of fructose due to hydrolysis of inulin on heating to dissolve it (Durbin and Rose, 1969), and allowance for this should be made. This can easily be done by the method described below.

\section{Methods}

Inulin was measured by the AutoAnalyzer adaptation by Dawborn (1965) of the Heyrovsky (1956) 3-indolylacetic acid method. The following points not mentioned by Dawborn were found to be important: (1) because of the strong acids used, ordinary transmission tubing cannot be used and glass transmission tubing should be used wherever possible; Acidflex tubing is used at junctions ; (2) Acidflex tubing, changed at frequent intervals, is used for the pump line which delivers strong hydrochloric acid; (3) Solvaflex tubing is essential for the indolylacetic pump line; (4) $2 \%$ indolylacetic acid was found superior to $0.5 \%$ recommended by Dawborn (1965); and (5) Brij was used in both dilute hydrochloric acid lines.

Each sample of plasma, urine, or infusate was analysed twice, once with the usual acid hydrolysis and once without in order to measure respectively total inulin + fructose and any other interfering substances, and then fructose plus interfering substances only. The difference between the two results is the true inulin.

\section{Infusion Procedure}

Patients were fasting and well hydrated before and during procedures by drinking water. They were recumbent except for micturition, where standing was encouraged in some cases. The inulin was a " $10 \%$ " solution (T. Kerfoot \& Co., Vale of Bardsley, Lancs.) and was given intravenously as a single priming dose of $30 \mathrm{ml} . / 70 \mathrm{~kg}$. body weight followed by a sustaining dose given at exactly $0.375 \mathrm{ml} . / \mathrm{min}$. for three to four hours. The sustaining dose was delivered by a $50-\mathrm{ml}$. syringe, the plunger of which was advanced via a synchronous motor (Unita II continuous infusion apparatus from Messrs. B. Braun, Germany). The rate of delivery was checked on numerous occasions and was found not to deviate from the pre-set rate. Each inulin infusion was continued for three to four hours, and five blood samples were taken during the last two to three hours of the infusion. Two or three accurately timed urine collections of 30 to 60 minutes each were made during each infusion, ordinary micturition without catheterization being used. Results are now reported of 16 inulin infusions on three normal volunteers, five patients with idiopathic hypercalciuria, and one with osteoporosis. None had oedema. It was possible to give a priming dose of inulin to two anephric and non-oedematous patients and study the resultant plasma inulin levels for the following 17 and 20 hours respectively. The inulin spaces were then calculated from the total inulin given and the final plasma inulin levels reached.

\section{Results}

The plasma inulin levels in the two anephric patients following priming doses of inulin are shown in Fig. 1. The inulin spaces were both $15 \cdot 11$.

A comparison of the inulin clearances calculated by the classical method (uv/p) and by the urineless method is shown in Fig. 2. In the case of the urineless method, only one result was obtained in each case, the plasma level used being the final constant level. In the case of the classical method, two or three answers were obtained in each case-that is, one answer for each period of urine collection-and the mean of these for each infusion has been presented. In some patients agreement between successive urine collections was good, but in some agreement was poor, and this is indicated in Fig. 2.

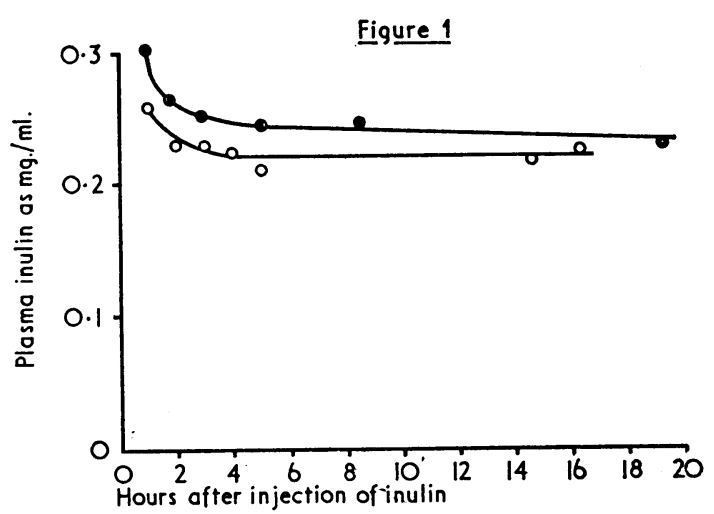

FIG. 1.-Plasma inulin levels following intravenous injection of a single shot of inulin in each of two anephric patients. The calculated inulin spaces were both $15 \cdot 1 \mathrm{l}$.

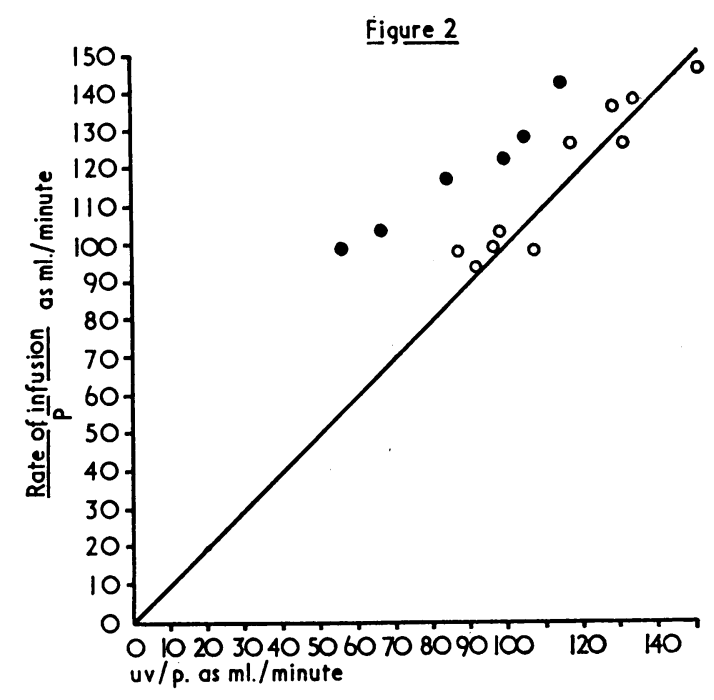

FIG. 2.-Comparison of inulin clearances calculated by the classical $u v / p$ and "urineless" rate of infusion $/ P$ methods respectively from data on each of 16 separate infusion studies. Open circles are from studies in which successive studies. Open circles are from studies in which successive clearance periods uv/p agreed well with each other, while the closed circles are where urine collections were clearly inaccurate as shown by widely differing values for successive urine collections (see text).

The final plasma inulin level varied between 26 and 42.5 $\mathrm{mg} . / 100 \mathrm{ml}$. In five of the infusions the plasma inulin levels varied by less than $\pm 1 \mathrm{mg}$. $/ 100 \mathrm{ml}$. during the course of the urine collections and such variations can certainly be ignored; in other infusions the variations were more marked and there was in general a tendency for the plasma inulin level to rise slightly during the last one and a half to two hours. Nevertheless, the classical method was considered valid, since the maximum variation of plasma inulin during any given urine collection was $0.3 \mathrm{mg} . / 100 \mathrm{ml}$. and the variation was usually much smaller than this.

\section{Discussion}

The reproducibility of the AutoAnalyzer method for inulin has been reported previously (Rose and Durbin, 1967) and need not be repeated here except to say it is highly satisfactory.

If the urineless technique is to be valid it is essential that certain conditions are satisfied. Firstly, the sole exit for inulin from the extracellular fluid should be through the kidneys. To show whether or not this was so, priming doses of inulin were given to two anephric patients. If there is no alternative exit for the inulin then the plasma level should become constant. Fig. 1 
shows that the results were satisfactory, since the plasma inulin level became virtually constant after three to four hours. It is inferred that this is the minimum time limit for an inulin infusion for the purpose of measurement of inulin clearance by the urineless technique. Secondly, the exact rate of infusion of inulin must be known. Not only must the exact volume of inulin solution infused per minute be known, but also the exact concentration. The latter is not known beforehand, since the mere heating of the solution to dissolve inulin results in some breakdown to fructose (Durbin and Rose, 1969). Therefore the infusate must be analysed for inulin and fructose separately and only the true inulin taken into account. This point is met in the technique described here by measuring the inulin with and without hydrolysis.

The agreement between clearances by the two techniques (with and without urine) appears at first sight to be rather poor (Fig. 2). A closer study, however, shows that there are two types of results, those where the two (or three) consecutive results from urine collections agreed well with each other and those in which they did not. In 10 studies the clearances calculated by the two methods differed by less than $12 \mathrm{ml}$./ minute, and in this group the mean range of clearances for successive urinary periods was $12.4 \mathrm{ml}$./minute. In six studies the clearances calculated by the two methods differed by $23-42$ $\mathrm{ml} . /$ minute, and the mean range of clearances for successive urinary periods was $25.9 \mathrm{ml}$./minute. These results are separately indicated in Fig. 2, and it is quite obvious that the two methods correlated poorly in those cases where the urine collections were unreliable, a result that is not at all surprising for specimens obtained without catheterization. On the other hand, when urine collections were reliable, as shown by good agreement for $u v / p$ in successive periods, these results correlated well with the urineless method. It should also be noted here that a large residual volume of urine would result in the urineless method giving a higher clearance value than the classical method, and this is well demonstrated in Fig. 2, where substantial disagreements between the two methods are always in this direction.

It is concluded that the urineless method of assessment of renal clearance devised by Earle and Berliner (1946) is satis- factory for inulin provided that an equilibration time of at least four hours is allowed for non-oedematous patients. This period of time is much longer than that used by Berger et al. (1948). An inulin infusion even of this length of time is scarcely even an inconvenience, however, for an inpatient if modern plastic intravenous catheters are used. This means that for non-oedematous individuals with good renal function an extremely simple method for measurement of inulin clearance can be used. It is only necessary to infuse the inulin at a known constant rate for four hours and measure the final plasma inulin level together with the concentration of inulin in the infusate. These measurements are readily and accurately carried out by the method described. The advantages of not having to collect urine do not require further mentioning. The advantage of using inulin is that, thanks to the extensive research of earlier workers (see Homer Smith, 1951), it seems that inulin clearance is a measure of glomerular filtration rate. Inulin is non-toxic, reasonably cheap, and it is not necessary to burden the patient with radioactive materials. It is suggested that the urineless method for measurement of glomerular filtration rate by means of inulin infusion should find widespread application for non-oedematous subjects.

I would like to thank Dr. A. R. Harrison and Dr. A. M. Joekes for allowing access to patients under their care, the volunteers for their services, Miss H. Durbin for technical assistance, and Sister Beckett for her assistance in the metabolic unit.

\section{REFERENCES}

Berger, E. Y., Farber, S. J., and Earle, D. P. (1948). Fournal of Clinical Investigation, 27, 710

Dawborn, J. K. (1965). Clinica Chimica Acta, 12, 63.

Durbin, H., and Rose, G. A. (1969). Submitted to Clinica Chimica Acta. Earle, D. P., and Berliner, R. W. (1946). Proceedings of the Society for Experimental Biology and Medicine, 62, 264.

Heyrovsky, A. (1956). Clinica Chimica Acta, 1, 470.

Robson, J. S., Ferguson, M. H., Olbrich, O., and Stewart, C. P. (1950). Quarterly fournal of Experimental Physiology, 35, 111.

Rose, G. A., and Durbin, H. (1967). Lancet, 2, 159.

Smith, H. W. (1951). The Kidney, Structure and Function in Health and Disease. New York, Oxford University Press.

\section{Preliminary Communications}

\section{Anti-Inflammatory Properties of Human Inflammatory Exudate}

British Medical fournal, 1969, 2, 93-96

S um ummary : An inflammatory exudate collected from a site of major surgery (partial gastrectomy) was found to possess definite anti-inflammatory properties when tested by the carrageenin oedema technique (a method widely adopted for the assessment of potential antirheumatic agents). Such anti-inflammatory properties could not be detected in the serum of normal healthy adults or in an abdominal ascites fluid. The active component in the exudate showed several properties in common with a similar anti-inflammatory substance present in inflammatory exudates of animal origin.

\section{INTRODUCTION}

More than a decade has passed since anti-inflammatory properties were first attributed to an inflammatory exudate (Rindani, 1956). The initial observation of Rindani has been confirmed several times with a number of inflammatory exudates of animal origin (DiPasquale and Girerd, 1961 ; DiPasquale, Girerd, Beach, and Steinetz, 1963 ; Robinson and Robson, 1964, 1966). Nevertheless, the presence of antiinflammatory properties, by which is meant the ability to inhibit experimental inflammatory reactions, has not as yst been described for an inflammatory exudate of human origin.

The early studies of Rindani (1956) established that the inflammatory exudate formed in the granuloma pouch in rats by injection of an irritant substance was capable of inhibiting in recipient rats formalin-induced arthritis of the hind foot. These findings stimulated DiPasquale and Girerd (1961) and 